
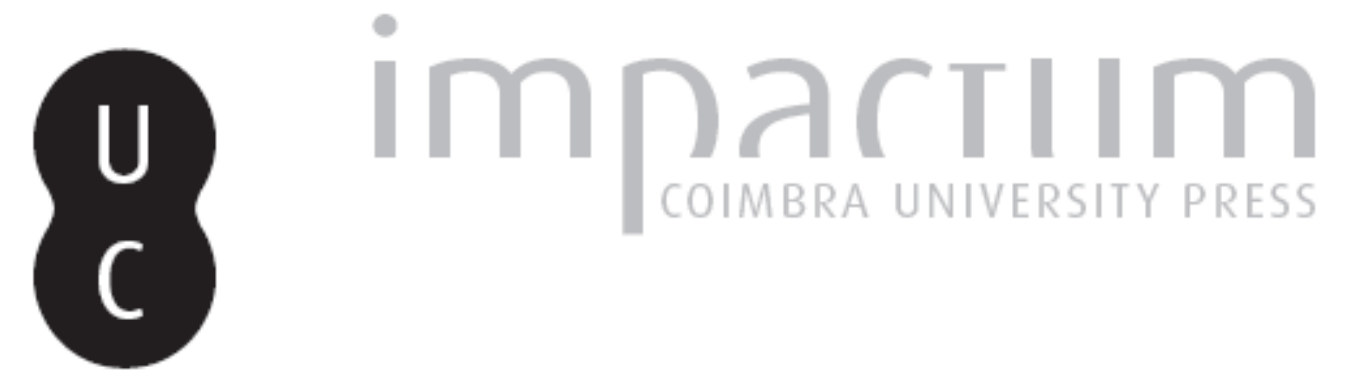

\title{
[Recensão a] Juana Rodríguez Cortés, Sociedad y Religión Clássica en la Bética Romana, Salamanca
}

\author{
Autor(es): D'Encarnação, José
}

Publicado por: Imprensa da Universidade de Coimbra

URL persistente:

URI:http://hdl.handle.net/10316.2/45539

DOI:

DOI:https://dx.doi.org/10.14195/1647-8657_30_17

Accessed : $\quad$ 26-Apr-2023 11:07:06

A navegação consulta e descarregamento dos títulos inseridos nas Bibliotecas Digitais UC Digitalis, UC Pombalina e UC Impactum, pressupõem a aceitação plena e sem reservas dos Termos e Condições de Uso destas Bibliotecas Digitais, disponíveis em https://digitalis.uc.pt/pt-pt/termos.

Conforme exposto nos referidos Termos e Condições de Uso, o descarregamento de títulos de acesso restrito requer uma licença válida de autorização devendo o utilizador aceder ao(s) documento(s) a partir de um endereço de IP da instituição detentora da supramencionada licença.

Ao utilizador é apenas permitido o descarregamento para uso pessoal, pelo que o emprego do(s) título(s) descarregado(s) para outro fim, designadamente comercial, carece de autorização do respetivo autor ou editor da obra.

Na medida em que todas as obras da UC Digitalis se encontram protegidas pelo Código do Direito de Autor e Direitos Conexos e demais legislação aplicável, toda a cópia, parcial ou total, deste documento, nos casos em que é legalmente admitida, deverá conter ou fazer-se acompanhar por este aviso.

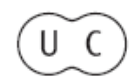


FACULDADE DE LETRAS

INSTITUTO DE ARQUEOLOGIA

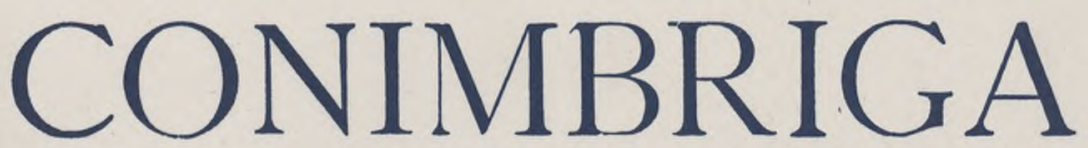

VOLUME XXX

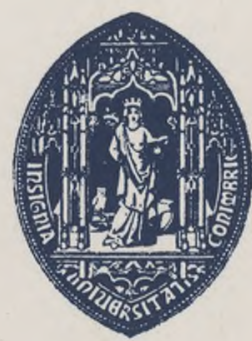

UNIVERSIDADE DE COIMBRA 
Juana Rodríguez Cortés, Sociedad y Religión Clássica en la Bética Romana, Salamanca, 1991. 148 pp. ISBN: 84-7481-624-6.

Tese de doutoramento apresentada, a 23 de Setembro de 1989, na Universidade de Salamanca.

Louve-se, em primeiro lugar, a iniciativa de dar à estampa o resultado duma investigação pacientemente levada a cabo durante vários anos e que, noutras circunstâncias, apenas aproveitaria a reduzido número de pessoas mais ou menos directamente ligadas à autora e à sua universidade.

Objectar-se-á que estes trabalhos carecem da maturidade que só o passar dos anos acrisola. Seja. Mas também não é menos verdade que tantos dados, tão cuidadosamente recolhidos, constituem importante manancial informativo de acesso, doutra sorte, bastante mais difícil.

Depois de, na introdução, dar conta dos objectivos da sua pesquisa e dos métodos utilizados, Juana Rodríguez Cortés debruçou-se, numa primeira parte, sobre os deuses do panteão romano cujo culto está dalguma forma documentado na Bética: por inscrições, vestígios arqueológicos (mormente iconográficos) ou numismas. Primeiro, a tríada capitolina: Júpiter, Juno e Minerva (pp. 23-38); depois, os outros, por ordem alfabética do seu nome latino (pp. 39-98).

Constitui esta, sem dúvida, a matéria fundamental da sua investigação, uma vez que aí comenta desenvolvidamente cada uma das epígrafes relativas ao tema em apreço, referindo, de modo particular, as características de cada uma das divindades, ao mesmo tempo que, com base em considerações de ordem onomástica, procura determinar o estatuto social dos dedicantes, aspecto que mais detidamente vai explorar na segunda parte do seu livro (pp. 99-122).

Conclui depois (pp. 123-125) que, na Bética, a implantação dos cultos oficiais acompanhou a par e passo a aculturação na sua globalidade. Desde muito cedo que os cultos aí se desenvolveram, bem à maneira latina e tendo como objecto as mesmas divindades e, como veículo, os mesmos rituais do Romano colonizador. Todas as «classes sociais» se encontram representadas entre os devotos, embora, como é natural, aos séxviros augustais — por serem libertos endinheirados, por a sua elevação ao sacerdócio do culto imperial lhes outorgar estatuto insigne - caiba, em termos de epígrafes, papel preponderante.

Quanto à distribuição geográfica das manifestações religiosas, Juana Rodríguez Cortés aponta a sua homogeneidade, com particular densidade apenas nas zonas mais urbanizadas. Em seu entender, mesmo a relativa escassez de testemunhos verificada no Noroeste da província se prende mais com a ausência de prospecções arqueológicas que a um real vazio de religiosidade.

Estas conclusões não se afastam, por conseguinte, do que seria normal esperar numa região tão intensamente valorizada pelos Romanos desde os primeiros tempos da sua vinda para a Península Ibérica. Mas tratava-se, na verdade, de uma pesquisa ainda não efectuada e, por isso, a obra de Juana Rodríguez constituirá, doravante, ponto de referência obrigatório, tanto mais que houve a preocupação de se compulsar uma bibliografia completa; podemos dizer que nenhum dos vestígios importantes foi 
omitido e que, no âmbito da análise antroponimica, poucas falhas há para apontar.

Completam a obra: um apêndice (pp. 129-137) em que as inscrições referidas são esquematicamente apresentadas em quadros de fácil percepção, pela ordem seguida no texto; e a bibliografia (pp. 139-146).

Como se trata dum bom instrumento de trabalho, cumpre-nos tecer sobre ele algumas considerações com vista a um eventual aprofundamento da reflexão sobre o tema.

Digamos, em primeiro lugar, que, por não serem muitos-uns 132, se não erro - talvez tivesse sido possível apostar numa tentativa de, mediante adequada revisão, se obter cuidadosa leitura de cada um dos textos. Aliás, embora saiba quanto isso encarece uma edição, teria sido agradável dispor de fotografias dos monumentos mais significativos ou, pelo menos, duma indicação precisa, sempre que viável, da sua tipologia. Exemplifico com algumas dúvidas que me surgiram:

- Na pág. 26, n. ${ }^{\circ} 4$ (CIL II1194): que é titulc(olonus)?

- Na pág. 32, n. ${ }^{\circ} 1$ (ILER 372), porque se desdobra em Badius, sem qualquer ponto de interrogação, o gentilicio de Fortunatus indicado na inscrição por meio de sigla?

- $\mathrm{O}$ n. ${ }^{\circ} 3$ da pág. 33 merecia duas, ainda que breves, reflexões. Em primeiro lugar, se o marido é vir clarissimus, Varínia Flacina deve ser c(larissima) f(emina): Juana Rodríguez Cortés manteve sem desdobrar as siglas C. f. apresentadas por José Vives (ILER 361) e sem dar delas qualquer interpretação. Por outro lado, teria sido oportuno assinalar a transmissão do gentilicio da mãe (e não do pai) para a filha, possível índice duma filiação natural.

- Concordo inteiramente com Juana Rodríguez quando afirma ser necessário duvidar da leitura feita por Mélida do texto 5 (perdido?) da pág. 34: depois de Licinius apenas viria o cognome do augustal e não a menção do seu patrono.

- O n. ${ }^{\circ} 4$ da pág. 37 (CIL II1950) pode ilustrar como a omissão da referência à tipologia do monumento nos priva dum dado essencial de análise. De facto, no caso vertente, será muito provavelmente a tipologia que nos ajudará a optar pela leitura Menerv(ae) Aug(ustae) de preferência a [I]mp. Nerva Aug. ou vice-versa.

- Na pág. 42, n. ${ }^{\circ} 2$ (CIL II 1610), em vez de per honorem, não se poderia reconstituir Tito $T V$, na medida em que falta a referência ao outro cônsul do ano 75 ? Não teria sido o nome de Tito alvo de posterior damnatio memoriae?

- Na pág. 61, n. ${ }^{\circ} 16$ (CIL II 1433), quiçá importaria ter discutido um pouco mais a leitura, porque se, como o comentário dá a entender, a dedicatória é ao Génio da Torre, deveria ler-se Turris Genio e não Turri Genio. Por outro lado, a palavra Genio costuma proceder o determinativo a que se refere e não ao invés. Cá está um dos casos em que muito interessaria saber se a inscrição foi revista e qual o seu paradeiro.

- No comentário ao n. ${ }^{\circ} 2$ da pág. 64 (CIL II1660 = ILER 205), regista-se uma ligeira confusão entre o praenomen imperator — que, de facto, Tibério nunca quis usar, para assim acentuar o carácter hereditário (não militar) do seu poder - e a saudação imperial, aqui desprovida de qualquer numeral por se tratar da primeira. Aliás, o texto - bastante controverso - não pode ser, por isso, datado do ano $14 \mathrm{~d}$. C., como Hübner propusera, mas sim muito provavelmente de 6-5 a. C., quando

Conimbriga, 30 (1991), 163-197 
Tibério, já adoptado por Augusto, ainda se designa Tib. Iulius Caesar (yide R. Cagnat,

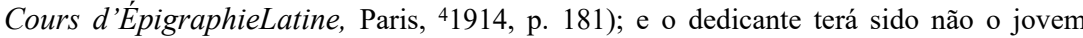
Tibério mas, muito provavelmente, o procônsul Q. Granius Marcianus, como Géza Alföldy teve oportunidade de propor (cf. Epigraphica Hispanica Vili - Eine kaiserliche Widmung in der Stadt Tucci, «Zeitschrift für Papyrologie und Epigraphik» 59 1985 189-199).

- Os números 8 a 10 da pág 66 terão sido, ao que parece, grafitos feitos em telhas. Desta sorte, a uma exclamação como Hercule (n. ${ }^{\circ} 10$ ) há que atribuir um grande valor histórico, porque parece grito de alma, vindo bem do fundo da devoção privada de quem (um escravo?) trabalhava na telheira. Toca-se, aqui, a religiosidade simples, despida das roupagens oficiais $-\mathrm{e}$ isso interessa-nos de modo especial.

- Por norma, um liberto imperial designa-se $A$ ug(usti) lib(ertus) e os escravos Caes(aris) ser(vus): cf. os artigos de P. R. C. Weaver, The Status Nomenclature of the Imperial Freedmen, "Classical Quaterly» 13 1963-1964 272-278 (sobretudo p. 273), e The Status Nomenclature of the Imperial Slaves, "Classical Quaterly» 14 1964 134-139 (sobretudo p. 139). Ora, no n. 2 da pág. 90 (ILER 310), a referência é, ao invés, $\operatorname{Aug}($ usti) ser(vus) — uma ocorrência, portanto, a assinalar.

- Na nota 44 da pág. 114, dá-se a entender que os cavaleiros documentados na epigrafia religiosa oficial da Bética nunca ultrapassaram a hierarquia das milícias equestres. Este é um dos aspectos curiosos da epigrafia provincial, a que ainda se não pôde dar resposta adequada, designadamente por ainda se não dispor de um banco de dados suficientemente amplo para abarcar todas as províncias do Império. Isto porque, como é natural, quando o cavaleiro assumia funções superiores às milícias preliminares da sua carreira, tinha forçosamente de ausentar-se para outras paragens onde as iria exercer. Não há, pois, motivo para nos admirarmos dessa falta de informação e certamente daqui a alguns anos o progresso dos estudos prosopográficos vai trazer-nos o complemento de muitos cursus honorum hoje considerados interrompidos.

Uma ou outra gralha tipográfica pode, aqui e além, provocar alguma perplexidade na interpretação dos textos. Assim:

- na pág. 47, n. ${ }^{\circ}$ (CIL II 1956), decerto se deverá 1er porticus public(as);

- na pág. 53, n. ${ }^{\circ} 3$ (CILII 2122), é, certamente, m(unicipum) M(unicipii) e não $M$ (unicipium) $m$ (unicipii);

- na pág. 58, n. ${ }^{\circ} 4$ (CIL II 1060), a dedicatória será Genio m(unicipii);

- na pág. 66, n. ${ }^{\circ} 12$ (CIL II 1929), o homenageado é Q. Cornelius Senecio Annianus, ou seja, $Q$ (uinto) Cornelio Senecioni Anniano, em dativo;

- na pág. 77, n. 3 (ILER $2080=6076$ ), temos uma estátua Mart(is) Aug(usti) oferecida pelo sumo pontífice do Município Triunfal —M(unicipii) Triumph(alis);

Ao abordarmos um tema com estas características, mormente se temos em mente determinar o papel que a religião — ou melhor, a atitude religiosa - deteve na sociedade, em determinada sociedade, há, do ponto de vista metodológico, duas ou três reflexões que importa fazer. 
1. Que significado atribuir à representação de divindades em moedas?

Escreve, a este propósito, Juana Rodríguez Cortés:

«As fontes numismáticas fornecem dados escassos, se considerarmos que grande parte das oficinas monetárias localizadas na área do nosso trabalho deixaram de cunhar moeda no espaço cronológico que vai de Tibério a Cláudio. Mas não depreciamos, por isso, o valor propagandístico da moeda, utilizada pelo poder público para emitir a sua propaganda religiosa» (p. 17).

Se, por um lado, é pouco significativo temporalmente o período que vai de Tibério a Cláudio (14-54 d. C.), de modo que essa não será objecção a ter em conta, afigura-se-me, por outro, que, no presente contexto, não há que considerar o «valor propagandístico da moeda» justamente porque o objectivo da pesquisa não é saber que divindades os imperadores queriam ver homenageadas mas sim que divindades eram, na prática, homenageadas de facto. Esta relação entre o que politicamente se pretende e realmente se consegue é que poderá constituir, na verdade, excelente campo de análise.

2. No que respeita aos vestígios arqueológicos (templos, esculturas, mosaicos, lucernas), pondera Juana Rodríguez Cortés (pp. 17-18) «que alguns desses objectos (sic) não tiveram relação com o culto e que o aparecimento duma divindade numa lucema, escultura, mosaico, pode ser devido a motivos extra-religiosos, como o auge popular de um mito, o gosto individual, etc.».

Estamos aqui no âmago da questão, que se prende necessariamente com o sentido profundo da religião e das suas manifestações. Até onde vai a «estética» e onde começa a «religião». E, aqui, verdade seja dita, não vai imprimir no disco duma lucerna a figura da deusa Vitória — em vez duma cena erótica — quem não sentir pela divindade o mínimo de veneração! Não vai um proprietário do século IV pedir que os mosaicos da sua villa tenham cenas de bacantes, se é um cristão convicto! Como não se invoca a protecção de Marte para o ente querido, se o deus da guerra não for da sua especial predilecção... A distinção a fazer-se residirá, sim, volto a insistir, não nestes aspectos mas na relação entre o que é «orientação» (digamos assim) oficial e o que, na realidade, acontece. Como é que a população acolheu essa orientação.

3. O caso das estátuas merece, neste âmbito, uma atenção particular. E até gostaria de ter visto o assunto abordado, com algum promenor, a propósito de CIL II2121 (pág. 77, n. ${ }^{\circ}$ 3), um dos raros exemplos de ofertas públicas de estátuas a Marte Augusto (identifiquei recentemente um terceiro exemplo na Península Ibérica, em Sines, porto da costa ocidental da Lusitânia); do $n .^{\circ} 3$ da pág. 40 , sobre que a informação é tão escassa; ou, ainda, do n. ${ }^{\circ} 2$ (perdido?) da pág. 5 (CIL II 6277).

A estátua oferecida por um magistrado municipal destina-se à praça pública. E é sintoma não apenas dum culto individual mas também, necessariamente, dum culto muito bem acolhido por toda a comunidade. Como fonte histórica, uma estátua reveste-se, pois, teoricamente e na prática, de um significado muito maior que a árula destinada a singelo laràrio familiar ou a invocação feita em contexto funerário.

4. Daí, o que atrás dizia acerca da tipologia do monumento.

Ao omitirmos esse dado, estamos, na verdade, a descurar uma informação fundamental. O texto duma inscrição é importante, não há dúvida; mas o texto requer um suporte; e o suporte enquadrava-se num contexto. E é nesta íntima relação entre 
a epígrafe e o seu enquadramento que reside parte significativa do seu valor como documento histórico.

Exemplifico:

CIL II21 foi por mim considerado uma placa, porque desde que se identificara que estivera embutido na parede dum edifício (Inscrições Romanas do Conventus Pacensis, Coimbra, 1984, p. 218). Dedicada por Gaio Átio Januário ao deus Esculápio postulava, como placa que era, a existência dum templete onde primitivamente fora encastrada. Como a inscrição se referia à realização de festas, imaginar-se-ia ainda a sua integração numa qualquer parede de recinto festivo. Sucede, porém, que, retirado o monumento da parede, se verificou ser uma ara com mais de um metro de altura. O contexto inicial terá sido, portanto, totalmente diferente e diferente é também o significado a atribuir-lhe: ganhou novo argumento a tese que defendia a presença dum templo a Esculápio em Santiago do Cacém e, por conseguinte, a existência duma grande devoção a esta divindade por parte dos habitantes sai, agora, substancialmente reforçada.

A este propósito, caberá referir o caso do n. ${ }^{\circ} 2$ da pág. 45 , porque sendo (como referem M. Pastor e A. Mendoza, $o . c$.) não um altar onde se fizessem sacrifícios mas uma réplica em ponto pequeno, constituirá ex-voto privado a que a ausência de menção do dedicante confere particular significado por assinalar um local de culto a esta divindade.

Este, um dos aspectos que gostaria de ver mais explicitado num dos próximos trabalhos de Juana Rodríguez Cortês.

E notória a falta de bibliografia portuguesa nas bibliotecas universitárias espanholas. Estamos a tentar suprir pouco a pouco essa lacuna. Leite de Vasconcelos é, por exemplo, o único autor português aqui referenciado, mas não consultado, porque senão, na pág. 143, teria sido citado o volume III (1913) d'As Religiões da Lusitânia, que trata das divindades clássicas, e não o II, que se ocupa das divindades indígenas. Nos corpora de inscrições já publicados relativos ao território actualmente português poderia a Autora ter encontrado interessantes paralelos para algumas das epígrafes.

Também um índice onomástico e outro dos textos do CIL II e das ILER estudados facilitaria, de futuro, a consulta da obra.

Note-se, porém, que estes comentários só foram possíveis porque Juana Rodríguez Cortés já fez o livro. Esse, um dos seus méritos. Sem pretensões, Sociedad y Religion Clásica en la B ética Romana atinge o objectivo fixado: dar uma panorâmica do que se sabe, aflorando, aqui e além, questões de pormenor a requererem análise mais aprofundada. Uma análise agora tornada possível a partir da síntese elaborada.

José D'ENCARNAÇão 